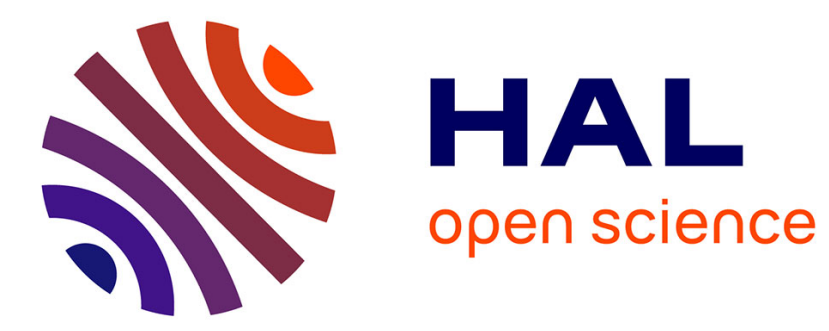

\title{
Amérique du Nord: d'importants changements dans le système des villes
}

Gérard-François Dumont

\section{To cite this version:}

Gérard-François Dumont. Amérique du Nord: d'importants changements dans le système des villes. Population et avenir, 2011, 705, pp.3. 10.3917/popav.705.0003 . halshs-00762281

\section{HAL Id: halshs-00762281 https://shs.hal.science/halshs-00762281}

Submitted on 6 Dec 2012

HAL is a multi-disciplinary open access archive for the deposit and dissemination of scientific research documents, whether they are published or not. The documents may come from teaching and research institutions in France or abroad, or from public or private research centers.
L'archive ouverte pluridisciplinaire HAL, est destinée au dépôt et à la diffusion de documents scientifiques de niveau recherche, publiés ou non, émanant des établissements d'enseignement et de recherche français ou étrangers, des laboratoires publics ou privés. 


\section{Amérique du Nord : d'importants changements dans le système des villes}

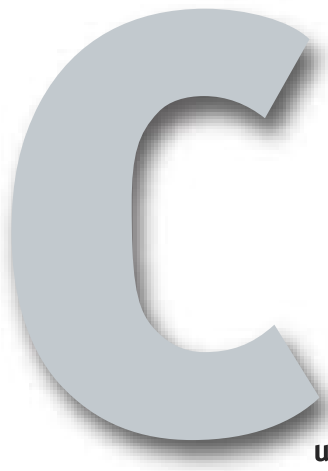

par Gérard-François DUMONT les pays à constitution fédérale, comme l'Allemagne, la population urbaine se répartit selon les villes sans qu'aucune n'ait un poids démographique écrasant. Qu'en est-il en Amérique du Nord?

La règle courante rappelée ci-dessous s'y constate dans les deux pays ${ }^{1}$, tous deux sous forme fédérale, le Canada et les États-Unis. Au Canada, l'agglomération la plus peuplée, Toronto, capitale de la province de l'Ontario, sur le grand lac qui porte le nom de la province, compte, en 2010, 5,4 millions d'habitants, soit 1,44 fois la population de la deuxième agglomération du pays, Montréal. Aux ÉtatsUnis, New York domine l'armature urbaine avec 19,5 millions d'habitants en 2010 , soit 1,5 fois la population de la deuxième agglomération la plus peuplée, Los Angeles. Dans ces deux pays, l'agglomération à la taille démographique la plus importante pèse moins de cinq fois la deuxième, ce rapport de taille supérieur ou égal à cinq étant le critère souvent utilisé pour définir un pays macrocéphale, comme la France avec Paris².

Ensuite, les agglomérations des deux pays situées aux rangs trois et quatre ont également un poids important. Au Canada, la troisième, Vancouver, la ville la plus peuplée de la Colombie Britannique ${ }^{3}$, compte 2,2 millions d'habitants, précédant trois autres villes millionnaires, Calgary en Alberta, Ottawa-Gatineau, la capitale fédérale, et Edmonton, la capitale de l'Alberta. Aux États-Unis, la troisième agglomération la plus peuplée, Chicago, compte, en 2010, 9,2 millions d'habitants, devançant Miami avec 5,7, Philadelphie, à peine moins, puis six villes entre 4 et 5 millions d'habitants.

Ces données montrent que les armatures urbaines des deux pays d'Amérique du Nord sont polycéphales, c'est-àdire qu'elles se distribuent en plusieurs villes dont les rapports de population entre deux villes de rang successifs ne sont jamais élevés.

Toutefois, l'analyse de ces deux armatures urbaines apparemment semblables doit être complétée par celle de leurs dynamiques. En comparant l'armature urbaine du Canada en 2010 par rapport à celle de 1950, deux changements sont mis en évidence :

- D’une part, le classement par rang des villes ${ }^{4}$ canadiennes a été bouleversé au Canada. Montréal, qui était la

\author{
L'ARMATURE URBAINE DU CANADA
}

\section{ET SES IMPORTANTS CHANGEMENTS}

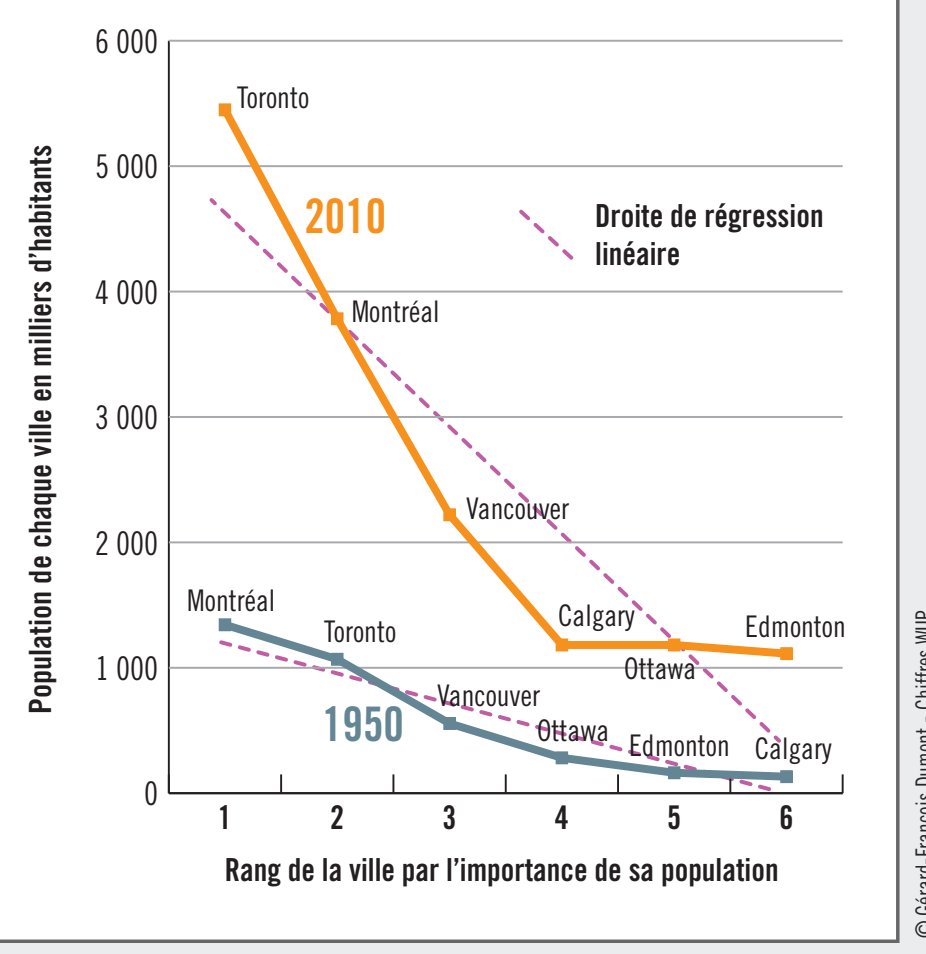

plus peuplée en 1950, s'est fait dépasser par Toronto. Vancouver est restée la troisième. Mais Calgary a doublé Ottawa et Edmonton pour se retrouver au même niveau de population qu'Ottawa.

- D’autre part, le Canada présente une polycéphalie moins régulière en 2010 qu'en 1950. En effet, en 1950, la corrélation entre le poids démographique des villes et leur rang était quasi-parfaite ${ }^{5}$. La figure montre des villes quasi-alignées sur une droite. En 2010, cette corrélation est encore élevée, mais a diminué. La figure indique effectivement que Toronto s'est détachée, puisque désormais placée nettement au-dessus de la droite de régression linéaire.

Aux États-Unis, le caractère polycéphale de l'armature urbaine de 1950 était mâtiné d'une tendance macrocéphale puisque la ville la plus peuplée, New York, pesait 2,5 fois la seconde, qui était alors Chicago. Deux changements sont intervenus :

\section{- Los Angeles a pris à Chicago la deuxième place.}

- En 2010, le rapport n'est plus que de 1,5 entre la première et la deuxième ville. Il apparaît désormais que les États-Unis demeurent à armature polycéphale, mais à tendance tricéphale par la domination de New York, Los Angeles et Chicago.

Ainsi, les effets de l'urbanisation peuvent donner des évolutions fort différentes. Paris, Sedes, 2010.
1. Nous considérons ici l'Amérique du Nord dans le découpage conventionnel des banques de données de l'ONU. 2. Dumont, Gérard-François (direction), La France en villes,

3. Mais non sa capitale qui est Victoria

4. En considérant les agglomérations comptant au moins rations comptant au moins 750000 habitants en 2010 selon les données WUP.

5. Pour ceux qui aiment les délices des mathématiques, le taux de corrélation de la droite de régression linéaire était de 0,91 , donc très proche de l'unité. 